\title{
Mycobacterium Tuberculosis Signaling via C-AMP
}

\author{
Mario Alberto Flores-Valdez ${ }^{1}$, Jeannette Barba ${ }^{2}$ and Angel H. Alvarez ${ }^{1}$ \\ ${ }^{1}$ Biotecnología Médica y Farmacéutica, CIATEJ, Guadalajara, Jalisco, \\ ${ }^{2}$ CUCBA, Universidad de Guadalajara, Guadalajara, Jalisco, \\ Mexico
}

\section{Introduction}

\subsection{Cyclic Adenosine Monophosphate (cAMP) metabolism in mycobacteria}

\subsubsection{General aspects of Adenylyl Cyclases and their presence in M. tuberculosis genomes}

Adelynate cyclases (ACs), which catalyze synthesis of cAMP from ATP and yield pyrophosphate as a by-product, can be classified into four different classes according to their common features: Class I cyclases, related to enterobacterial adenylate cyclases; Class II, toxic adenylate cyclases isolated from bacterial pathogens; Class III, a large and probably ancient class that comprises cyclases from both eukaryotes and prokaryotes and is strongly related to guanylate cyclases; and Class IV, with mainly one example that differs entirely from all other classes (McCue et al., 2000).

In class I ACs (the enterobacterial type) no long stretch of hydrophobic amino acid residues is present to explain the membrane-bound localization of the adenylate cyclases. In all cases, the proteins are very rich in cysteine residues, an uncommon feature for proteins located in the cytoplasm or at the cytoplasmic border of the membrane. They are also rich in histidine residues, which could indicate that metal ions take part in the folding and/or activity of the polypeptide chain (Mock et al., 1991).

Class II ACs (the calmodulin-activated toxic class) is represented by Bordetella pertussis adenylate cyclase. It is synthesized as a large bifunctional polypeptide chain of 1706 amino acid residues. The $\mathrm{N}$-terminal segment of the protein (400 residues) alone displays calmodulin-activated adenylate cyclase activity, whereas the rest of the molecule is responsible for hemolytic activity and for transporting the toxin. After attempts to isolate other members of this class, several examples of similar proteins have now been discovered in Bacillus anthracis, Pseudomonas aeruginosa, and in Yersinia species. Comparison of the catalytic regions of the B. pertussis and B. anthracis adenylate cyclases identified four conserved regions that are involved in catalysis, calmodulin binding and activation. The first region comprises a sequence, Gly-XXXX-Gly(Ala)-Lys-Ser, similar to the nucleotidebinding motif found in many ATP- or GTP-binding proteins. Analysis of the region conserved between the B. anthracis and B. pertussis enzymes, indicates that these proteins 
may form a catalytic center from the cooperation of two halves. The function of calmodulin may be to trigger the appropriate conformational change necessary to form an active catalytic center (Drum et al., 2002).

Class III ACs (the "universal" class) form a very diverse collection of enzymes in eubacteria. They comprise two domains: the catalytic domain is carboxy-terminal and the regulatory domain is likely an ion transporter in one case and the phosphorylated moiety of a twocomponent regulatory system in another. Most mammalian ACs are monomeric integral membrane proteins that are catalytically active as pseudoheterodimers (Sunahara et al., 1996), while prokaryotes and lower eukaryotes produce both soluble and membrane-bound nucleotidyl cyclases of variant domain compositions functioning as homodimers (Guo et al., 2001). In general, class III ACs are the most widespread class of cAMP-generating enzymes, and they are further subdivided into four subclasses: IIIa-IIId. Dimerization is required for all class III ACs in order to be active, given the substrate-binding sites are formed at the dimer interface (Abdel Motaal et al., 2006). Class III adenylyl and guanylyl cyclases are proteins with a central four stranded anti-parallel $\beta$-sheet structurally similar to the palm domain of DNA polymerases, and a-helices on either side (Shenoy \& Visweswariah, 2006b). So far, all Cyclase Homology Domain (CHDs) proteins operate as dimers with mostly two catalytic centers positioned at the dimer interface, where catalysis is based on six highly conserved residues. Two aspartate residues coordinate two metal cofactors ( $\mathrm{Mg} 2+$ or $\mathrm{Mn} 2+)$, an asparagine and an arginine stabilize the transition-state and a lysine-aspartate couple specifies ATP as a substrate. Several mycobacterial ACs gene products were early annotated as putative cyclases, but have now been characterized biochemically and structurally.

Class IV ACs was assigned to Aeromonas hydrophila, which synthesizes a very small cyclase of 193 residues. This class IV cyclase has an optimal temperature for activity of $65^{\circ} \mathrm{C}$ and is at least ten times more active than the class I adenylate cyclase in the same organism (Sismeiro et al., 1998). No function has yet been discovered for this protein. Currently, it has been found only in various isolates of $A$. hydrophila and in $Y$. pestis.

Most prokaryotes contain a single adenylate cyclase (AC, e.g. E. coli) and some contain none (e.g., Bacillus species); however, 16 or 17 genes have been identified as ACs in mycobacteria, and in particular M. tuberculosis. AC enzymes require the presence of conserved metal-, substrate-binding (either ATP or GTP) amino acid residues and transition-state stabilizing amino acid residues in their catalytic site (Shenoy \& Visweswariah, 2006b).

The genome of $M$. tuberculosis H37Rv encodes 16 class III cyclases while the CDC1551 strain has 17 cyclases. Using the $16 \mathrm{H} 37 \mathrm{Rv}$ class III ACs genes as query, we found they posses different numbers of orthologous genes in the up-to-date sequenced mycobacterial genomes available at MycoDB (http://xbase.bham.ac.uk/mycodb/, Table 1). This suggests that some of these cyclases have more conserved roles than others. Several mycobacterial gene products initially classified as cyclases have now been biochemically and structurally characterized as ACs. In mycobacteria, they retain similar catalytic properties to the mammalian enzymes, in terms of the requirement for divalent cations, and dimerization as a prerequisite to generate the catalytic site.

Bioinformatics analysis has predicted subcellular localization of mycobacterial ACs (Shenoy et al., 2004). Nevertheless, experimental studies have identified proteins like Rv0386 and Rv1358 in mycobacterial cell wall and membranes, despite the absence of 
hydrophobic, predicted transmembrane domains (Agarwal, 2009). This suggests that a necessary improvement to prediction software must emphasize these particularities of mycobacteria.

\begin{tabular}{|l|r|}
\hline Gene name & Orthologous (No.) \\
\hline$R v 0386$ & 7 \\
\hline$R v 0805$ & 7 \\
\hline$R V 0891 c$ & 4 \\
\hline$R v 1264$ & 13 \\
\hline$R v 1318 c$ & 14 \\
\hline$R v 1319 c$ & 14 \\
\hline$R v 1320 c$ & 14 \\
\hline$R v 1358$ & 7 \\
\hline$R v 1359$ & 3 \\
\hline$R v 1625 c$ & 11 \\
\hline$R v 1647$ & 16 \\
\hline$R v 1900 c$ & 10 \\
\hline$R v 2212$ & 6 \\
\hline$R v 2564$ & 3 \\
\hline$R v 2565$ & 3 \\
\hline$R v 3645$ & 16 \\
\hline
\end{tabular}

Table 1. Orthologous to H37Rv AC-domain containing genes present in Mycobacteria

As mycobacteria lack G-proteins, it is unknown how bacterial adenylate cyclase AC activities are modulated. However, polyphosphates isolated from $M$. bovis BCG were potent inhibitors of Rv1625c, Rv1264, and Rv3645, and the mechanism of inhibition proposed is that polyphosphates possibly obstructs the catalytic fold of ACs (Guo et al., 2001).

\section{2 cAMP producing (Adenylyl cyclases) and degrading (Phosphodiesterase) mycobacterial enzymes}

Six M. tuberculosis AC-domain containing proteins (Rv0891c, Rv1264, Rv1359, Rv1647, Rv2212 and Rv1625c) contain just a cyclase domain. Rv1647 and Rv1625c are phylogenetically distant and biochemically distinct AC-domain containing proteins (Shenoy \& Visweswariah, 2006a). The remaining AC-domain containing proteins have additional domains that presumably allow them to respond to multiple signals, regulate their activity in response to environmental conditions, and/or expand their repertoire with effector function capability. Five of these multidomain AC-domain containing proteins (Rv1318c, Rv1319c, Rv1320c, Rv2435c and Rv3645c) are membrane-associated and contain HAMP (histidine kinases, adenylyl cyclases, methyl-accepting chemotaxis proteins and phosphatases) domains. HAMP domains are often associated with two-component signal transduction pathways and connect the sensing of extracellular environmental signals with 
responding intracellular signalling domains. Mycobacterial ACs with HAMP domains have six transmembrane regions, followed by the HAMP domain and a C-terminal AC domain. Modulators of $M$. tuberculosis AC activity include $\mathrm{pH}$ and fatty acids, which were seen to enhance the $\mathrm{pH}$ sensitivity of the holoenzyme, and $\mathrm{CO}_{2}$ levels, and could be signals present during M. tuberculosis host infection (Abdel Motaal et al., 2006, Bai et al., 2011, Barba et al., 2010).

An N-terminal autoregulatory domain in Rv1264 is a pH-response element that inhibits cyclase activity above $\mathrm{pH}$ 6.0. Additional AC-domain containing proteins (Rv0386, Rv1358 and Rv2488c) posses both ATPase and helix- turn-helix (HTH) domains. Rv1900c contains an $\alpha \beta$-hydrolase domain (Barba et al., 2010, Bai et al., 2011). Rv0386 is the first AC-domain containing protein as a representative of the family of putative DNA-binding domaincontaining cyclases in mycobacteria (Castro et al., 2005). Rv0386 has guanylyl cyclase activity that is $20 \%$ of its adenylyl cyclase activity.

Rv1625c adenylyl cyclase is particularly unusual, in that it is catalytically active when expressed in mammalian cells or in E. coli. The Rv1264 holoenzyme shows higher AC activity at acidic $\mathrm{pH}(\mathrm{pH}$ 6.0). Similarly, the Rv1264 AC is activated only at low $\mathrm{pH}(\mathrm{pH}$ 5.5) whereas Rv1647 is active only at high $\mathrm{pH}$ ( $\mathrm{pH} 8.5)$. The localization of Rv1647 in the cell wall and membrane fractions of $M$. tuberculosis might enable the bacteria to sense and respond to extracellular $\mathrm{pH}$ shifts. Because $M$. tuberculosis actively avoids phagosomal acidification, sensing of $\mathrm{pH}$ and bicarbonate and/or $\mathrm{CO}_{2}$ could be crucial signaling events in M. tuberculosis pathogenesis (Shenoy \& Visweswariah, 2006a). In fact, cAMP production in pathogenic mycobacteria increased when the $\mathrm{pH}$ of their growth medium was shifted from $\mathrm{pH} 6.7$ to $\mathrm{pH} 5.5$ (Gazdik et al., 2009), thus suggesting activation of the acidresponsive ACs.

In M. tuberculosis, Rv0998 was recently shown to regulate protein lysine acetylation in a cAMP-responsive manner (Nambi et al., 2010), where acetylation is enhanced in the presence of either cAMP or cGMP. Recently, it was shown that a cAMP-dependent protein acetyltransferase inactivates ACs through acetylation of a single, specific lysine residue, and Rv1151c is a NAD+-dependent deacetylase that reactivates ACs. This acetylation/deacetylation system in mycobacteria is likely to sense the extracellular environment through cAMP levels and also key intracellular metabolites, including NAD+ and $\mathrm{AcCoA}$, since $\mathrm{CAMP}, \mathrm{AcCoA}$, and NAD+ are required for acetylation and deacetylation, respectively (Xu et al., 2011).

Adenylyl cyclase Rv2212 from M. tuberculosis has a domain composition identical to the $\mathrm{pH}$ sensing isoform Rv1264, an N-terminal regulatory domain and a C-terminal catalytic domain. The maximal velocity of Rv2212 was the highest of all 10 mycobacterial cyclases investigated to date. Unsaturated fatty acids strongly stimulated Rv2212c activity by increasing substrate affinity (Findeisen et al., 2007). In addition, fatty acids greatly enhanced the $\mathrm{pH}$ sensitivity of the holoenzyme, thus converting $\mathrm{Rv} 2212 \mathrm{c}$ to a $\mathrm{pH}$ sensor adenylyl cyclase (Abdel Motaal et al., 2006).

To date, the only identifiable cAMP phosphodiesterase (PDE) in the genome of $M$. tuberculosis H37Rv is the one encoded by the Rv0805 gene. This enzyme is a dimeric $\mathrm{Fe}(3+)-$ $\mathrm{Mn}(2+)$ binuclear PDE, where metals coordinated at the catalytic site contribute to dimerization and thus play an additional structural role apart from their involvement in 
catalysis (Shenoy et al., 2007). As this gene is found only in pathogenic mycobacteria, Rv0805 may therefore play a key role in the pathogenicity of mycobacteria, not only by hydrolyzing bacterial cAMP, but also by indicating as a protein that can alter cell wall functioning (Podobnik et al., 2009).

\section{Participation of cyclic adenosine $3^{\prime}, 5^{\prime}$-monophosphate (cAMP) in mycobacterial gene regulation}

Cyclic adenosine $3^{\prime}, 5^{\prime}$-monophosphate (cAMP) is one of the most important second messengers used in bacteria and it has been characterized principally in Escherichia coli. However its signaling role in $M$. tuberculosis is beginning to emerge. A large number of AC genes are present in Mycobacterium tuberculosis in comparison with other microorganims (Cha et al., 2010, Klengel et al., 2005, Shenoy et al., 2004), and also that Mycobacterium just have one class III cNMP phosphodiesterase (Rv0805) that has been identified in $M$. tuberculosis (McCue et al., 2000, Shenoy et al., 2007) with a modest ability to efficiently hydrolyse 3 ',5'-cAMP and that responds to $\mathrm{H}_{2} \mathrm{O}_{2}$ in vitro (Bai et al., 2011, Barba et al., 2010). cAMP may serve as both an extra and intracellular signaling molecule in mycobacteria (Agarwal, 2009). cAMP levels are modulated by stress conditions in M. smegmatis, where it has been found in concentrations between $10 \mu \mathrm{M}$ and $1 \mathrm{mM}$, suggesting that cAMP participates in signalling events within the bacterial cell, mediating its action by downstream effectors (Dass et al., 2008).

It appears that Mycobacteria need to maintain a steady level of cytoplasmatic cAMP in many conditions. For example, it has been shown that cytoplasmic cAMP levels in E. coli are reduced three- to fourfold when the carbon source is $\sim 0.2 \%$ glucose rather than glycerol (Bai et al., 2011). In contrast, a recent study showed no significant change in the cytoplasmic cAMP levels of $M$. bovis BCG incubated with $0.2 \%$ glucose (Bai et al., 2009), or carbonstarved bacteria (Dass et al., 2008). cAMP levels decrease in both fast- and slow-growing mycobacteria in response to very high levels of glucose (2\%) (Bai et al., 2011). cAMP levels have been suggested to be high in Mycobacterium cells, exceeding up to 100-fold levels found in other bacteria (Nambi et al., 2010, Stapleton et al., 2010, Shenoy \& Visweswariah, 2006b, Rickman et al., 2005). However, it is difficult to make a comparison between studies, due to cAMP variations presents in the conditions tested, as well as the different normalization and reporting methods used.

\subsection{CRP and CNMP binding proteins}

In silico studies predict $10 \mathrm{cNMP}$ binding proteins that encompass a wide range of potential effector functions, suggesting a more complex role for cAMP signalling, probably important during host infection. From these 10 cNMP binding proteins, 7 (Rv0073, Rv0104, Rv2434c, Rv2564, Rv2565, Rv3239c and Rv3728) contain an assortment of putative functional domains, including those associated with transport functions and esterase activities (McCue et al., 2000, Shenoy \& Visweswariah, 2006a). Only three cNMP binding proteins have been functionally characterized to date (Bai et al., 2011). Two of these proteins, referred to as CRP (Rv3676, for Catabolite Represor Protein) and Cmr (Rv1675c, for cAMP and macrophage regulator), contain a HTH DNA binding domains, and belong to the CRP-FNR family of transcription factors (McCue et al., 2000). The third protein from this group, is encoded by 
Rv0998 in M. tuberculosis, and regulates lysine acetylation in mycobacterial proteins in a cAMP-responsive manner (Nambi et al., 2010). The biological effects of this acetylation are not yet defined.

CRP (cAMP receptor protein) in Escherichia coli, is one of the best-studied prokaryotic transcription factor. Currently, a total of 378 target promoters on the Escherichia coli genome are proposed to be under the control of cAMP-bound CRP, using a SELEX approach (Shimada et al., 2011). Some of the CRP regulon genes include those encoding the transporters and the catabolic enzymes of glucose (Perrenoud \& Sauer, 2005) and nonglucose sugars (Wickstrum et al., 2010), virulence genes (Espert et al., 2011), motility genes (Hollands et al., 2010), GMP synthesis (Husnain et al., 2009), anaerobic growth and nitrate reductases genes (Stewart et al., 2009). To date, in E. coli, 2 differents ways in which CRP leads the sigma 70 promoter trancription have been described: in the Class I promoters, CRP binds upstream of the promoter -35 element, at a site centered at position -61.5 or further upstream, and an activating region (AR1) in the downstream subunit of the CRP dimer makes contact with the C-terminal domain of one of the two RNA polymerase a subunits (aCTD). In class II promoters, CRP binds at a target that overlaps the promoter -35 element and is usually centered at position -41.5. AR1 in the upstream subunit of the CRP dimer interacts with aCTD, while a second activating region (AR2) in the downstream subunit interacts with the N-terminal domain of one of the two RNA polymerase a subunits (aNTD)(Hollands et al., 2010).

In a similar manner to the CRP protein from E. coli, the M. tuberculosis CRP (Rickman et al., 2005 ) is the best-studied example of a protein implicated in cAMP-mediated signaling. In $M$. tuberculosis CRP is encoded by the gene Rv3676 and it is homologous to E. coli CRP. In E. coli, it has been shown that CRP regulates expression of genes required to control metabolism, as well as growth under hypoxic and nutrient-deprived conditions. Like E. coli CRP, M. tuberculosis Rv3676 possesses an N-terminal cAMP-binding domain and a C-terminal DNAbinding domain. The crystal structures of M. tuberculosis CRP at 2.2 and 2.0 A resolution of cAMP-bound (Reddy et al., 2009) and the apo-form (Gallagher et al., 2009), have been reported. Conformational changes required for DNA-binding do not take place in the absence of the second messenger (Reddy et al., 2009). In fact, as opposed to E. coli CRP where cAMP binding follows a cooperative mechanism, c-AMP binding sites are independent, and DNA-binding activity is not as enhanced with M. tuberculosis Rv3676

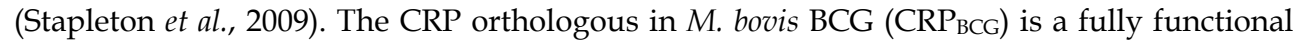
transcription factor, since $\mathrm{CRP}_{\mathrm{BCG}}$ overcame the virulence deficiency of an $M$. tuberculosis crp mutant (Hunt et al., 2008). Although both of them have a similar ability to bind cAMP and DNA, $\mathrm{CRP}_{\mathrm{BCG}}$ 's DNA binding affinity is approximately twice that of Mycobacterium tuberculosis CRP (CRP $\mathrm{Mt}_{\mathrm{Mt}}$ ) (Bai et al., 2007, Hunt et al., 2008). Interestingly, $\mathrm{CRP}_{\mathrm{BCG}}$ differs from $\mathrm{CRP}_{\mathrm{Mt}}$ in just two amino acid residues (L47P and E178K).

The other predicted cAMP-dependent transcriptional regulator, $\mathrm{Cmr}$, was found to negatively regulate the expression of five proteins (GroEL2, Rv2971, PE_PGRS6a, Mdh and Rv1265) (Gazdik \& McDonough, 2005). The upstream regions of three of these genes (mdh, groEL2 and Rv1265) bound specifically to Cmr in electrophoretic mobility shift assays, consistent with direct regulation of these genes by Cmr. Expression of three of these genes was found to be regulated within macrophages, and this regulation was mediated by $\mathrm{Cmr}$ in both M. tuberculosis and M. bovis BCG (Gazdik et al., 2009). Despite 
the importance of $\mathrm{Cmr}$ for the cAMP- dependent regulation of these genes, $\mathrm{Cmr}$ has not been shown to directly bind cAMP in vitro, and cAMP did not affect Cmr's binding to any of their promoter sequences (Gazdik et al., 2009). The mechanism by which Cmr responds to cAMP levels has yet to be discovered, and it is possible that a second factor plays a facilitating role.

\section{2 $\mathrm{CRP}_{\mathrm{Mt}}$ regulon}

The cAMP binding transcriptional regulator encoded by Rv3676 in M. tuberculosis has been strongly associated with growth during mycobacterial life cycle. Its deletion resulted in impaired growth in macrophage cell lines and in mice (Hunt et al., 2008, Rickman et al., 2005). Using an exponential enrichment (SELEX) approach, Bai et al. defined the CRP $P_{\text {Mt's }}$ palindromic binding motif (C/TGTGANNNNNNT CACG/A) based on 58 predicted binding sites from the $M$. tuberculosis genome, using a combination of $E$. coli CRP binding sites and $M$. tuberculosis DNA sequences recovered by affinity capture using $\mathrm{CRP}_{\mathrm{Mt}}$ to seed the computational analyses (Bai et al., 2005). Akhter et al. used the positional Shannon relative entropy method to predict 19 new putative binding sites for $M$. tuberculosis (Rv3676) CRP, in addition to the 73 sites previously predicted by Bai et al. (Akhter et al., 2008, Bai et al., 2005). These additional sites resulted from a difference where Akhter et al. used only the information available from the $M$. tuberculosis CRP-regulon instead of adding up the one available from the E.coli CRP-regulon. According to Akhter et al., the M. tuberculosis CRPregulon comprises genes required for critical functions like: (i) cell-wall biogenesis, (ii) central metabolism pathways, (iii) putative regulatory elements controlling cAMP signaling, and (iv) antibiotic resistance (Akhter et al., 2008) (Table 2).

Experimental validation of these predictions has only been completed for Bai et al. model (Bai et al., 2005). Their research showed that mutation of nucleotides G2 or C15 from the palindromic binding motif, abolished $\mathrm{CRP}_{\mathrm{Mt}}$ 's binding. Both positions are conserved in all predicted binding sites. They also evaluated $\mathrm{CRP}_{\mathrm{Mt}}$ and $\mathrm{CRP}_{\mathrm{BCG}}$ binding to seven putative $\mathrm{CRP}_{\mathrm{Mt}}$ sites, located within intergenic regions, where 6 out of these 7 were found to be functional in vitro and in vivo (Bai et al., 2007). This increases confidence in the prediction algorithm that was used to identify $\mathrm{CRP}_{\mathrm{Mt}}$ binding sites, although at this point it is possible to suggest that $C R P_{M t}$ regulon requires further refinement. On the other hand, it has been shown that $r p f A$ is directly activated by $\mathrm{CRP}_{\mathrm{Mt}}$ (Rickman et al., 2005). The resuscitationpromoting factor (Rpf) is a growth factor that stimulates the growth of aged M. tuberculosis cultures, and members of this family are thought to play a role in reactivation of dormant $M$. tuberculosis (Mukamolova et al., 2002). Regulation of rpfA by $\mathrm{CRP}_{\mathrm{Mt}}$ suggests that $\mathrm{CRP}_{\mathrm{Mt}}$ plays a role in persistence and/or reactivation of tuberculosis, but this is only one of many biological functions that may be regulated by $\mathrm{CRP}_{\mathrm{Mt}}$ in $M$. tuberculosis.

Expression of M. tuberculosis whiB1, a member of the $\mathrm{Wbl}$ (WhiB-like) family, is controlled positively and negatively by $\mathrm{CRP}_{\mathrm{Mt}}$ (Stapleton et al., 2010; Agarwal et al., 2006). A CRP $\mathrm{Pt}_{\mathrm{Mt}}$ binding site (CRP $\left.\mathrm{Mt}_{\mathrm{Mt}} 1\right)$ was detected in whiB1's upstream regulatory region (Smith et al., 2010) (Rickman et al., 2005). Reporter assays with native and mutated promoter sequences indicated that transcription from the native, but not the mutant, promoter was affected by cAMP levels via the direct binding with $C_{\text {Mt }}$ (Agarwal et al., 2006). Other evidences indicate that a second $\mathrm{CRP}_{\mathrm{Mt}}$ binding site $\left(\mathrm{CRP}_{\mathrm{Mt}} 2\right)$ in the whiB1 promoter altered $\mathrm{CRP}_{\mathrm{Mt}}$ 's 


\begin{tabular}{|c|c|c|}
\hline Associated function & Gene & Predicted function \\
\hline \multirow{5}{*}{ Cell-wall biogenesis } & Rv0993 & $\begin{array}{l}\text { galU, uridine diphosphate-glucose } \\
\text { pyrophosphorylase }\end{array}$ \\
\hline & Rv3031 & \multirow{2}{*}{$\begin{array}{l}\text { Members of the family of enzymes } \\
\text { transferring activated sugars }\end{array}$} \\
\hline & Rv3032 & \\
\hline & $R v 0643 c$ & mma3, methoxy mycolic acid synthase \\
\hline & $R v 0904 c$ & $\begin{array}{l}\text { AccD3, a putative acetyl CoA carboxylase } \\
\text { carboxyl transferase, which catalyzes the } \\
\text { initial steps of fatty acid and mycolic acid } \\
\text { biosynthesis. }\end{array}$ \\
\hline \multirow{7}{*}{$\begin{array}{l}\text { Central metabolism } \\
\text { pathways }\end{array}$} & $R v 2918$ & $g \ln D$, uridyl transferase \\
\hline & Rv0992c & $\begin{array}{l}\text { CHP with putative 5-formyltetrahydrofolate } \\
\text { cyclo-ligase }\end{array}$ \\
\hline & Rv0520 & $\begin{array}{l}\text { Methyl transferase believed to be involved in } \\
\text { ubiquinone pathway }\end{array}$ \\
\hline & Rv3113 & Phosphatase \\
\hline & Rv3114 & Nucleoside deaminase \\
\hline & Rv3505 & $\begin{array}{l}\text { FadE27, protein possibly involved in } \\
\text { regulating probable acyl-CoA dehydrogenase }\end{array}$ \\
\hline & $R v 3617$ & EphA, putative epoxide hydrolase \\
\hline \multirow{3}{*}{$\begin{array}{l}\text { Putative regulatory } \\
\text { elements controlling } \\
\text { cAMP signaling }\end{array}$} & Rv0104 & $\begin{array}{l}\text { Hypothetical protein probably implied in } \\
\text { cAMP mediated signaling in } M \text {. tuberculosis }\end{array}$ \\
\hline & $R v 0103 c$ & Probable cation transporter \\
\hline & $R v 3645$ & \multirow[t]{2}{*}{ Membrane linked adenylyl cyclase } \\
\hline \multirow{4}{*}{ Antibiotic resistance } & Rv0906 & \\
\hline & Rv0907 & $\begin{array}{l}\text { Hypothetical proteins belonging to the } \\
\beta \text {-lactamase family }\end{array}$ \\
\hline & Rv0905 & echA6, enoyl-CoA hydratase \\
\hline & Rv0908 & CtpE, methyl-accepting chemotaxis protein \\
\hline
\end{tabular}

Table 2. Mycobaterium genes belonging to CRP regulon and their associated function

regulatory effect inhibiting whiB1 expression (Stapleton et al., 2010). Interestingly, only $\mathrm{CRP} 1_{\mathrm{Mt}}$ enhances whiB1 expression, while $\mathrm{CRP} \mathrm{Mt}_{\mathrm{Mt}} 2$ alone represses whiB1 expression. Dnase I footprinting assays allowed to determine the presence at -58.5 of an activating $\mathrm{CRP}_{\mathrm{Mt}}$ binding site (CRP $\mathrm{Mt} 1)$, which matches in seven of the eight nucleotides from the proposed $\mathrm{CRP}_{\mathrm{Mt}}$ consensus (NGTGNNANNNNNCACA), and also it overlapped with the repressing $\mathrm{CRP}_{\mathrm{Mt}}$ binding site $\left(\mathrm{CRP} \mathrm{Mt}_{\mathrm{Mt}} 2\right)$ centred at -37.5 . This second site has a poorer match to the consensus (six of the eight defined bases are matched)(Stapleton et al., 2010, Rickman et al., 2005). CRP ${ }_{\text {Mt }} 1$ site was occupied before the $C P_{M t} 2$ site by a titration test done with increasing concentrations of $\mathrm{CRP}_{\mathrm{Mt}}$. It is worth noting that although it was shown that cAMP enhanced binding of recombinant $\mathrm{CRP}_{\mathrm{Mt}}$ to target DNA, this enhancement was not equivalent to that observed for $E$. coli CRP, where DNA-binding affinity is enhanced by several orders of magnitude in the presence of $0.1 \mathrm{mM}$ cAMP, allowing specific DNA binding at nanomolar concentrations. For $\mathrm{CRP}_{\mathrm{Mt}}$, a much less significant enhancement of DNA binding was observed, and higher concentrations of cAMP compared with E.coli CRP were required (Stapleton et al., 2010). 
On the other hand, out of 92 genes found and predicted by bioinformatics to be regulated by CRP in M. tuberculosis, only 18 [including echA6, ctpE, accD3, sucC, sucD, glnD, fadE9, fbpC1 (Ag85C) and gall] have conserved orthologous in $M$. leprae, M. avium subsp. paratuberculosis, and M. smegmatis (Akhter et al., 2008). Incorporation of a plasmid harboring and expressing M. tuberculosis Rv3676 in an M. tuberculosis strain in which Rv3676 was absent, induced differential expression of 27 genes when compared to the same mutant harboring the BCG gene orthologous to Rv3676 (Hunt et al., 2008). This constitutes evidence that differences in gene regulatory sequences or the regulators among species exist, and it could explain the number of genes that do not respond in a similar manner. Further characterization of the M. tuberculosis CRP regulon as well as analysis of what physiological conditions regulate activation/inactivation are required.

\section{Participation of CAMP in mycobacterial pathogenic processes}

Little is known about the role of cAMP in mycobacteria, although it is found in both pathogenic and non-pathogenic species. Ingestion of live M. microti or M. bovis BCG (but not M. lepraemurium) increased macrophage intracellular cAMP levels, whereas no change occurred in cells engulfing dead bacilli, latex beads or colloidal gold (Lowrie et al., 1979). The rise in cAMP levels appears directly related to mycobacterial capacity to interfere with phagolysosome formation, evidence suggesting that these microorganisms modify cAMPdependent signalling pathways as a manner to control virulence and infection (Lowrie et al., 1975, Lowrie et al., 1979). Elevated cAMP levels were correlated with reduced phagolysosome fusion during mycobacterial infection of macrophages (Kalamidas et al., 2006). Increased cAMP levels inside phagocytes were shown to negatively modulate actindependent processes, including chemotactic movement and phagocytosis. Macrophage passage was found to have a stimulatory effect on cAMP production by mycobacteria, as cAMP levels within macrophage-passaged mycobacteria were $\sim 50$-fold higher than cAMP levels within bacteria incubated in the tissue culture medium alone (Bai et al., 2009).

Evidences exist that cAMP regulates gene expression in mycobacteria during bacterial growth in vitro (Stapleton et al., 2010, Dass et al., 2008), and during macrophage infection (Rickman et al., 2005) where some studies identified $\mathrm{Cmr}$ as a transcription factor that regulates cAIGs (cAMP-iduced genes) within macrophages, and suggest that multiple factors affect cAMP-associated gene regulation in tuberculosis-complex mycobacteria (Gazdik et al., 2009). Even during phagocytosis, expression may be down regulated in response to high CAMP or NO levels inside the macrophage environment, providing a mechanism to integrate the transcriptional response to two important signals associated with infection (Smith et al., 2010). Generally, increases in cAMP levels compromise the bactericidal activity of the host immune system.

It is likely that each cyclase is associated with a distinct signaling pathway. It is expected that specific cyclases are activated to modify cAMP levels in response to different physiological conditions as for example hypoxia, intramacrophage enviroment or $\mathrm{pH}$ changes. cAMP receptor protein (CRP) Rv3676 was found to exist as dimmer and exhibited cAMP binding in a concentration-dependent manner and could bind specifically to the putative CRP/FNR nucleotide sequence elements in response to hypoxia (Akhter et al., 2008). The protein itself is composed of three distinct regions of the polypeptide: a large Nterminal domain that binds cAMP, a long $\alpha$-helix (termed the C-helix) that mediates most of 


\begin{tabular}{|c|c|c|}
\hline Gene & Induction & Repression \\
\hline Rv0386 & $\begin{array}{l}\text { Palmitic acid } \\
\text { Tetracyclin }\end{array}$ & $\begin{array}{l}\text { 7H9 medium shaking } \\
\text { Streptomyicin } \\
\text { Purified surfactant lipids }\end{array}$ \\
\hline Rv0891c & Oleic acid & DETA/NO \\
\hline Rv1120c & Pulmonary surfactant & Non-replicative persistence \\
\hline$R v 1264$ & Carbonyl cyanide chlorophenylhydrazone & $\begin{array}{l}\text { Palmitic acid } \\
\text { DETA/NO }\end{array}$ \\
\hline$R v 1318 c$ & $\begin{array}{l}\text { Oligopeptide permease (Rv3662c-Rv3665c) mutant } \\
\text { Palmitic acid }\end{array}$ & $\begin{array}{l}\text { Pulmonary surfactant protein A (human) } \\
\text { Acetate }\end{array}$ \\
\hline Rv1319c & Hypoxia & $\begin{array}{l}\text { Arachidonic acid } \\
\text { Hydrogen peroxide } \\
\text { Tioridazine } \\
\text { Nicotinamide } \\
\end{array}$ \\
\hline Rv1320c & Acetate & \\
\hline Rv1359 & $\begin{array}{l}\text { Econazole } \\
\text { Macrophages } \\
\text { Iron }\end{array}$ & $\begin{array}{l}\text { Arachidonic acid } \\
\text { Palmitic acid }\end{array}$ \\
\hline$R v 1625 c$ & $\begin{array}{l}\text { Clofazimine + S-nitrosoglutathione } \\
\text { Arachidonic acid } \\
\text { Thioridazine }\end{array}$ & $\begin{array}{l}\text { Palmitic acid } \\
\text { Oleic acid }\end{array}$ \\
\hline Rv1647 & $\begin{array}{l}\text { Linoleic acid } \\
\text { Palmitic acid } \\
\text { Oleic acid } \\
\end{array}$ & $\begin{array}{l}\text { Streptomyicin } \\
\text { Arachidonic acid } \\
\text { DETA/NO }\end{array}$ \\
\hline$R v 1900 c$ & $\begin{array}{l}\text { Non-replicative persistence } \\
\text { PA } 824 \\
\text { Palmitic acid }\end{array}$ & $\begin{array}{l}\text { Tetracycline } \\
\text { S-nitrosogluthatione + Chlorpromazine } \\
\text { Acetate }\end{array}$ \\
\hline Rv2212 & Tetracycline & 5-chloro-pyrazinamide \\
\hline Rv2345 & Starvation & $\begin{array}{l}\text { Thioridazine } \\
\text { DETA/NO }\end{array}$ \\
\hline$R v 2488 \mathrm{c}$ & $\begin{array}{l}\text { Arachidonic acid } \\
\text { Acetate }\end{array}$ & $\begin{array}{l}\text { Tetracycline } \\
\text { Palmitic acid } \\
\text { Hydrogen peroxide }\end{array}$ \\
\hline $\operatorname{Rv3645}$ & Oleic acid & $\begin{array}{l}\text { Oligopeptide permease }(R v 3662 c-R v 3665 c) \text { mutant } \\
\text { Acetate } \\
\text { Ceramide }\end{array}$ \\
\hline
\end{tabular}

Table 3. Growth conditions afecting expression of mycobacterial cyclase domain containing genes 
the inter monomer interactions, and a small C-terminal DNA-binding domain. It is also capable of binding to two, three, or four cAMP molecules, but the specificity of recognition sequentially diminishes beyond two cAMP molecules bound to CRP, although the physiological importance of this molecular interactions are not yet known (Stapleton et al., 2010). Data available at Tuberculosis Database (http://www.tbdb.org/, Table 3) might help suggesting particular conditions where each AC gene may be required.

Currently, few studies have addressed the participation of cAMP signalling in $M$. tuberculosis pathogenesis in vivo. Rickman et al. (Rickman et al., 2005) found that a mutant in Rv3676 (CRP) had diminished bacterial burden in lung and spleen after intravenous infection of BALB/c mice, compared to wild type bacteria. On the other hand, Agarwal et al. (Agarwal et al., 2009) found that a Rv0386 M. tuberculosis mutant was affected in its capacity to replicate in BALB/c or C57BL/6 mice lungs, following aerosol infection. Neither publication mentioned the capacity of either strain to kill mice.

In addition to determining bacterial burden in infected lungs Agarwal et al. (Agarwal et al., 2009) demonstrated that cAMP produced by M. tuberculosis Rv0386 during J774.16 macrophage infection was a substrate for protein kinase $A$, in order to control the amount of phosphorylated CREB (CREB-P), by using specific chemical inhibitors of selected signalling transduction pathways. They found CREB-P induced TNF- $\alpha$ production, and led to an unregulated host inflammatory response, which favoured bacterial survival. To date, this is the first indication of how adenylyl cyclase action helps sustaining an infection by pathogenic mycobacteria.

\section{References}

Abdel Motaal, A., I. Tews, J. E. Schultz \& J. U. Linder, (2006) Fatty acid regulation of adenylyl cyclase Rv2212 from Mycobacterium tuberculosis H37Rv. FEBS J 273: 4219-4228.

Agarwal, N., \& W.R. Bishai, (2009) cAMP signaling in Mycobacterium tuberculosis. Indian J Exp Biol 47: 393-400.

Agarwal, N., G. Lamichhane, R. Gupta, S. Nolan \& W. R. Bishai, (2009) Cyclic AMP intoxication of macrophages by a Mycobacterium tuberculosis adenylate cyclase. Nature 460: 98-102.

Agarwal, N., T. R. Raghunand \& W. R. Bishai, (2006) Regulation of the expression of whiB1 in Mycobacterium tuberculosis: role of cAMP receptor protein. Microbiology 152: 2749-2756.

Akhter, Y., S. Yellaboina, A. Farhana, A. Ranjan, N. Ahmed \& S. E. Hasnain, (2008) Genome scale portrait of cAMP-receptor protein (CRP) regulons in mycobacteria points to their role in pathogenesis. Gene 407: 148-158.

Bai, G., M. A. Gazdik, D. D. Schaak \& K. A. McDonough, (2007) The Mycobacterium bovis BCG cyclic AMP receptor-like protein is a functional DNA binding protein in vitro and in vivo, but its activity differs from that of its M. tuberculosis ortholog, Rv3676. Infect Immun 75: 5509-5517.

Bai, G., G. S. Knapp \& K. A. McDonough, (2011) Cyclic AMP signalling in mycobacteria: redirecting the conversation with a common currency. Cell Microbiol 13: 349-358. 
Bai, G., L. A. McCue \& K. A. McDonough, (2005) Characterization of Mycobacterium tuberculosis Rv3676 (CRPMt), a cyclic AMP receptor protein-like DNA binding protein. J Bacteriol 187: 7795-7804.

Bai, G., D. D. Schaak \& K. A. McDonough, (2009) cAMP levels within Mycobacterium tuberculosis and Mycobacterium bovis BCG increase upon infection of macrophages. FEMS Immunol Med Microbiol 55: 68-73.

Barba, J., A. H. Alvarez \& M. A. Flores-Valdez, (2010) Modulation of cAMP metabolism in Mycobacterium tuberculosis and its effect on host infection. Tuberculosis (Edinb) 90: 208-212.

Castro, L. I., C. Hermsen, J. E. Schultz \& J. U. Linder, (2005) Adenylyl cyclase Rv0386 from Mycobacterium tuberculosis H37Rv uses a novel mode for substrate selection. FEBS J 272: 3085-3092.

Cha, P. H., S. Y. Park, M. W. Moon, B. Subhadra, T. K. Oh, E. Kim, J. F. Kim \& J. K. Lee, (2010) Characterization of an adenylate cyclase gene (cyaB) deletion mutant of Corynebacterium glutamicum ATCC 13032 (vol 85, pg 1061, 2010). Appl Microbiol Biot 86: 395-395.

Dass, B. K., R. Sharma, A. R. Shenoy, R. Mattoo \& S. S. Visweswariah, (2008) Cyclic AMP in mycobacteria: characterization and functional role of the Rv1647 ortholog in Mycobacterium smegmatis. J Bacteriol 190: 3824-3834.

Drum, C. L., S. Z. Yan, J. Bard, Y. Q. Shen, D. Lu, S. Soelaiman, Z. Grabarek, A. Bohm \& W. J. Tang, (2002) Structural basis for the activation of anthrax adenylyl cyclase exotoxin by calmodulin. Nature 415: 396-402.

Espert, S. M., E. A. Elsinghorst \& G. P. Munson, (2011) The tib adherence locus of enterotoxigenic Escherichia coli is regulated by cyclic AMP receptor protein. J Bacteriol 193: 1369-1376.

Findeisen, F., J. U. Linder, A. Schultz, J. E. Schultz, B. Brugger, F. Wieland, I. Sinning \& I. Tews, (2007) The structure of the regulatory domain of the adenylyl cyclase Rv1264 from Mycobacterium tuberculosis with bound oleic acid. J Mol Biol 369: 1282-1295.

Gallagher, D. T., N. Smith, S. K. Kim, H. Robinson \& P. T. Reddy, (2009) Profound asymmetry in the structure of the cAMP-free cAMP Receptor Protein (CRP) from Mycobacterium tuberculosis. J Biol Chem 284: 8228-8232.

Gazdik, M. A., G. Bai, Y. Wu \& K. A. McDonough, (2009) Rv1675c (cmr) regulates intramacrophage and cyclic AMP-induced gene expression in Mycobacterium tuberculosis-complex mycobacteria. Mol Microbiol 71: 434-448.

Gazdik, M. A. \& K. A. McDonough, (2005) Identification of cyclic AMP-regulated genes in Mycobacterium tuberculosis complex bacteria under low-oxygen conditions. J Bacteriol 187: 2681-2692.

Guo, Y. L., T. Seebacher, U. Kurz, J. U. Linder \& J. E. Schultz, (2001) Adenylyl cyclase Rv1625c of Mycobacterium tuberculosis: a progenitor of mammalian adenylyl cyclases. EMBO J 20: 3667-3675.

Hollands, K., D. J. Lee, G. S. Lloyd \& S. J. Busby, (2010) Activation of sigma 28-dependent transcription in Escherichia coli by the cyclic AMP receptor protein requires an unusual promoter organization. Mol Microbiol 75: 1098-1111.

Hunt, D. M., J. W. Saldanha, J. F. Brennan, P. Benjamin, M. Strom, J. A. Cole, C. L. Spreadbury \& R. S. Buxton, (2008) Single nucleotide polymorphisms that cause structural changes in the cyclic AMP receptor protein transcriptional regulator of 
the tuberculosis vaccine strain Mycobacterium bovis BCG alter global gene expression without attenuating growth. Infect Immun 76: 2227-2234.

Husnain, S. I., S. J. Busby \& M. S. Thomas, (2009) Downregulation of the Escherichia coli guaB promoter by upstream-bound cyclic AMP receptor protein. J Bacteriol 191: 6094-6104.

Kalamidas, S. A., M. P. Kuehnel, P. Peyron, V. Rybin, S. Rauch, O. B. Kotoulas, M. Houslay, B. A. Hemmings, M. G. Gutierrez, E. Anes \& G. Griffiths, (2006) cAMP synthesis and degradation by phagosomes regulate actin assembly and fusion events: consequences for mycobacteria. J Cell Sci 119: 3686-3694.

Klengel, T., W. J. Liang, J. Chaloupka, C. Ruoff, K. Schroppel, J. R. Naglik, S. E. Eckert, E. G. Mogensen, K. Haynes, M. F. Tuite, L. R. Levin, J. Buck \& F. A. Muhlschlegel, (2005) Fungal adenylyl cyclase integrates $\mathrm{CO} 2$ sensing with cAMP signaling and virulence. Curr Biol 15: 2021-2026.

Lowrie, D. B., V. R. Aber \& P. S. Jackett, (1979) Phagosome-lysosome fusion and cyclic adenosine 3':5'-monophosphate in macrophages infected with Mycobacterium microti, Mycobacterium bovis BCG or Mycobacterium lepraemurium. J Gen Microbiol 110: 431-441.

Lowrie, D. B., P. S. Jackett \& N. A. Ratcliffe, (1975) Mycobacterium microti may protect itself from intracellular destruction by releasing cyclic AMP into phagosomes. Nature 254: 600-602.

McCue, L. A., K. A. McDonough \& C. E. Lawrence, (2000) Functional classification of cNMPbinding proteins and nucleotide cyclases with implications for novel regulatory pathways in Mycobacterium tuberculosis. Genome Res 10: 204-219.

Mock, M., M. Crasnier, E. Duflot, V. Dumay \& A. Danchin, (1991) Structural and functional relationships between Pasteurella multocida and enterobacterial adenylate cyclases. J Bacteriol 173: 6265-6269.

Mukamolova, G. V., O. A. Turapov, D. I. Young, A. S. Kaprelyants, D. B. Kell \& M. Young, (2002) A family of autocrine growth factors in Mycobacterium tuberculosis. Mol Microbiol 46: 623-635.

Nambi, S., N. Basu \& S. S. Visweswariah, (2010) cAMP-regulated protein lysine acetylases in mycobacteria. J Biol Chem 285: 24313-24323.

Perrenoud, A. \& U. Sauer, (2005) Impact of global transcriptional regulation by ArcA, ArcB, Cra, Crp, Cya, Fnr, and Mlc on glucose catabolism in Escherichia coli. J Bacteriol 187: 3171-3179.

Podobnik, M., R. Tyagi, N. Matange, U. Dermol, A. K. Gupta, R. Mattoo, K. Seshadri \& S. S. Visweswariah, (2009) A mycobacterial cyclic AMP phosphodiesterase that moonlights as a modifier of cell wall permeability. J Biol Chem 284: 32846-32857.

Reddy, M. C., S. K. Palaninathan, J. B. Bruning, C. Thurman, D. Smith \& J. C. Sacchettini, (2009) Structural insights into the mechanism of the allosteric transitions of the mycobacterium tuberculosis cAMP receptor protein. J Biol Chem.

Rickman, L., C. Scott, D. M. Hunt, T. Hutchinson, M. C. Menendez, R. Whalan, J. Hinds, M. J. Colston, J. Green \& R. S. Buxton, (2005) A member of the cAMP receptor protein family of transcription regulators in Mycobacterium tuberculosis is required for virulence in mice and controls transcription of the rpfA gene coding for a resuscitation promoting factor. Mol Microbiol 56: 1274-1286. 
Shenoy, A. R., M. Capuder, P. Draskovic, D. Lamba, S. S. Visweswariah \& M. Podobnik, (2007) Structural and biochemical analysis of the Rv0805 cyclic nucleotide phosphodiesterase from Mycobacterium tuberculosis. J Mol Biol 365: 211-225.

Shenoy, A. R., K. Sivakumar, A. Krupa, N. Srinivasan \& S. S. Visweswariah, (2004) A Survey of Nucleotide Cyclases in Actinobacteria: Unique Domain Organization and Expansion of the Class III Cyclase Family in Mycobacterium tuberculosis. Comp Funct Genomics 5: 17-38.

Shenoy, A. R. \& S. S. Visweswariah, (2006a) Mycobacterial adenylyl cyclases: biochemical diversity and structural plasticity. FEBS Lett 580: 3344-3352.

Shenoy, A. R. \& S. S. Visweswariah, (2006b) New messages from old messengers: cAMP and mycobacteria. Trends Microbiol 14: 543-550.

Shimada, T., N. Fujita, K. Yamamoto \& A. Ishihama, (2011) Novel Roles of cAMP Receptor Protein (CRP) in Regulation of Transport and Metabolism of Carbon Sources. PLoS ONE 6: e20081.

Sismeiro, O., P. Trotot, F. Biville, C. Vivares \& A. Danchin, (1998) Aeromonas hydrophila adenylyl cyclase 2: a new class of adenylyl cyclases with thermophilic properties and sequence similarities to proteins from hyperthermophilic archaebacteria. $J$ Bacteriol 180: 3339-3344.

Smith, L. J., M. R. Stapleton, G. J. Fullstone, J. C. Crack, A. J. Thomson, N. E. Le Brun, D. M. Hunt, E. Harvey, S. Adinolfi, R. S. Buxton \& J. Green, (2010) Mycobacterium tuberculosis WhiB1 is an essential DNA-binding protein with a nitric oxidesensitive iron-sulfur cluster. Biochem J 432: 417-427.

Stapleton, M., I. Haq, D. M. Hunt, K. B. Arnvig, P. J. Artymiuk, R. S. Buxton \& J. Green, (2009) Mycobacterium tuberculosis cAMP receptor protein (Rv3676) differs from the Escherichia coli paradigm in its cAMP-binding, DNA-binding and transcription activation properties. J Biol Chem.

Stapleton, M., I. Haq, D. M. Hunt, K. B. Arnvig, P. J. Artymiuk, R. S. Buxton \& J. Green, (2010) Mycobacterium tuberculosis cAMP receptor protein (Rv3676) differs from the Escherichia coli paradigm in its cAMP binding and DNA binding properties and transcription activation properties. J Biol Chem 285: 7016-7027.

Stewart, V., P. J. Bledsoe, L. L. Chen \& A. Cai, (2009) Catabolite repression control of napF (periplasmic nitrate reductase) operon expression in Escherichia coli K-12. J Bacteriol 191: 996-1005.

Sunahara, R. K., C. W. Dessauer \& A. G. Gilman, (1996) Complexity and diversity of mammalian adenylyl cyclases. Annu Rev Pharmacol Toxicol 36: 461-480.

Wickstrum, J. R., J. M. Skredenske, V. Balasubramaniam, K. Jones \& S. M. Egan, (2010) The AraC/XylS family activator RhaS negatively autoregulates rhaSR expression by preventing cyclic AMP receptor protein activation. J Bacteriol 192: 225-232.

Xu, H., S. S. Hegde \& J. S. Blanchard, (2011) Reversible Acetylation and Inactivation of Mycobacterium tuberculosis Acetyl-CoA Synthetase Is Dependent on cAMP. Biochemistry 50: 5883-5892. 


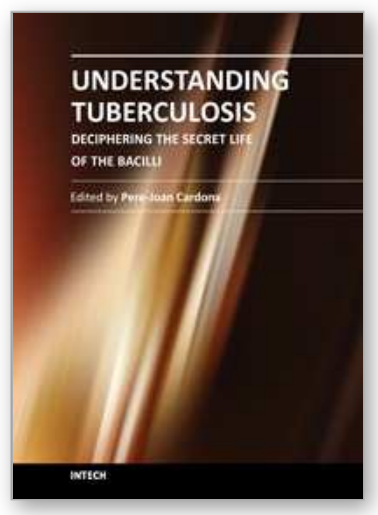

\author{
Understanding Tuberculosis - Deciphering the Secret Life of the \\ Bacilli \\ Edited by Dr. Pere-Joan Cardona
}

ISBN 978-953-307-946-2

Hard cover, 334 pages

Publisher InTech

Published online 17, February, 2012

Published in print edition February, 2012

Mycobacterium tuberculosis, as recent investigations demonstrate, has a complex signaling expression, which allows its close interaction with the environment and one of its most renowned properties: the ability to persist for long periods of time under a non-replicative status. Although this skill is well characterized in other bacteria, the intrinsically very slow growth rate of Mycobium tuberculosis, together with a very thick and complex cell wall, makes this pathogen specially adapted to the stress that could be generated by the host against them. In this book, different aspects of these properties are displayed by specialists in the field.

\title{
How to reference
}

In order to correctly reference this scholarly work, feel free to copy and paste the following:

Mario Alberto Flores-Valdez, Jeannette Barba and Angel H. Alvarez (2012). Mycobacterium Tuberculosis Signaling via c-AMP, Understanding Tuberculosis - Deciphering the Secret Life of the Bacilli, Dr. Pere-Joan Cardona (Ed.), ISBN: 978-953-307-946-2, InTech, Available from:

http://www.intechopen.com/books/understanding-tuberculosis-deciphering-the-secret-life-of-thebacilli/mycobacterium-tuberculosis-signaling-via-c-amp

\section{INTECH}

open science | open minds

\section{InTech Europe}

University Campus STeP Ri Slavka Krautzeka 83/A 51000 Rijeka, Croatia Phone: +385 (51) 770447

Fax: +385 (51) 686166 www.intechopen.com

\section{InTech China}

Unit 405, Office Block, Hotel Equatorial Shanghai No.65, Yan An Road (West), Shanghai, 200040, China 中国上海市延安西路65号上海国际贵都大饭店办公楼405单元 Phone: +86-21-62489820

Fax: $+86-21-62489821$ 
(C) 2012 The Author(s). Licensee IntechOpen. This is an open access article distributed under the terms of the Creative Commons Attribution 3.0 License, which permits unrestricted use, distribution, and reproduction in any medium, provided the original work is properly cited. 